\title{
MÜLEMMA VE ABDÜLVÂSİ-İ CEBELÎ
}

\author{
Sevda Aygar Bacanl1 ${ }^{*}$ \\ Tülay Koyun**
}

\section{$\ddot{\mathbf{O} z}$}

Aynı vezin ve kafiyede olmak koşuluyla bir mısra veya beyit Arapça, bir mısra veya beyit Farsça olarak nazmedilen şiirlere verilen isim olan mülemma, X. yüzyılda Fars Edebiyatı'nda ortaya çıkmıştır. Şehîd-i Belhî'nin öncüsü olduğu mülemma türü şiir Senâî, Mevlana, Sa'dî Şirazî, Hâfiz gibi Arapça'ya vakıf olan güzide şairlerin şiirlerinde görülmüştür.

$\mathrm{Bu}$ çalışmada adı geçen şairler kadar meşhur olmayan ancak XII. yüzyılda yaşamış, Fars Edebiyatı'nda engin Arapça bilgisi ile tanınan "zu'l-belagateyn" şairlerden Abdülvâsi-i Cebelî̀nin hayatı ve edebî kişiliği hakkında bilgi verilmiştir. Aynı yüzyılda Fars şiir üslûbunun değişimine katkı sağlayarak döneme damgasını vuran Mes'ûd-i Sa'd, Ebu'l-Ferec Rûnî, Senâî gibi şairler arasında yer alması açısından önem arz eden Cebelî, kasidelerinde Arapça kelimeleri sıkça kullanmış ve karşımıza mülemma şairi olarak çıkmıştır. Bu bağlamda Cebelî̀nin bir beyit Arapça, bir beyit Farsça olarak kaleme aldığı kasidesi tercüme edilip dil, üslûp açısından incelenerek, mülemma şiiri tanıtılmaya çalışılmıştır. Ayrıca mülemmanın Fars ve Arap Edebiyatları'ndaki yerine değinilmiş, o dönemde Arapça'nın Farsça üzerindeki etkisi ve önemi dile getirilmeye çalışılmıştır.

Anahtar Kelimeler: Fars Edebiyat1, Arap Edebiyat1, İran, Fars şiiri, Mülemma, Abdülvâsi-i Cebelî.

\section{Mulamma' and 'Abdu'l-Wâsi Jabalî}

\section{Abstract}

"Mulamma'" (macaronic), which is defined as a poetic composition containing verses in Arabic and others in Persian providing that the same rhyme and meter, has appeared in the tenth century Persian Literature. This type of poem whose pioneer is Şehîd-i Belhî, has seen

\footnotetext{
*Arş. Gör., Ankara Üniversitesi, Dil ve Tarih-Coğrafya Fakültesi, Doğu Dilleri ve Edebiyatları Bölümü, Fars Dili ve Edebiyatı Anabilim Dalı, e-posta: aygar@ankara.edu.tr
}

** Arş. Gör., Ankara Üniversitesi, Dil ve Tarih-Coğrafya Fakültesi, Doğu Dilleri ve Edebiyatları Bölümü, Arap Dili ve Edebiyatı Anabilim Dalı, e-posta: tkoyun@ankara.edu.tr 
in the poems of eminent poets such as Senâî, Jalalu'd-Dîn Rumî, Sa'dî Shirâzî, Hâfiz who are a mastery over both languages.

In this work, it's been surveyed the literary identity and the life of 'Abdu'l-Wâsi' Jabalî who isn't as famous as the poets mentioned but lived in the twelfth century that is known as one of the poet of "zu'lbelagateyn" who has knowledge in depth about Arabic and Persian Language. Jabalî, who is among the important poets such as Mes'ûd-i Sa'd, Abu'l-Faraj Rûnî, Senâî attracting attention by contributing to the evolution of the poetry style of Persian, didn't only use Arabic words frequently in his odes, but also he wrote the poem of mulamma'. In this context the mulamma of Jabalî which indited it by a couplet in Arabic and a couplet in Persian, has been presented which was surveyed in terms of language and literary style that's been translated from both Arabic and Persian Literature. Furthermore, it has been mentioned place of mulamma' in both literature and it has been tried to express the effect of Arabic on Persian Language and Literature and its importance at that time.

Keywords: Persian Literature, Arabic Literature, Iran, Persian Poem, Mulamma', 'Abdu'l-Wâsi' Jabalî.

\section{Giriş}

Arapçada mülemma' (ملمّع) kelimesi, parlamak ${ }^{l}$ anlamına gelen leme'a ( لمع ) kökünden türetilmiş mezîd fiil olan lemme'a (لمع (م) 'nın ism$\mathrm{i}$ mef'ûlüdür. fí fiili ise kumaşı çeşitli renklerle boyamak'; atın, elbisenin, taşın veya benzeri şeylerin farklı renklerden oluşması veya (atın vücudunda vb.) alacalı renk olmak ${ }^{3}$ şeklinde açıklanmıştır. Klasik Arap sözlüklerinin birçoğunda mülemma' (ملمّع) sözcüğü ise, çeşitli renklerden oluşan, renk renk, alacall ${ }^{4}$ anlamlarına gelmektedir.

Terim olarak klasik Arapça belagat kitaplarında bulunmayan mülemma, modern dönem bazı belagat kitaplarında şiir sanatlarından sayılmıştır. Nitekim "Mevsûa'tu 'Ulûmi'l-Lügati'l-Arabiyye" adlı eserde mülemmanın, Arap şiirinde her bir beyitin bir mısrası noktalı (مُعْجَمم) diğer misrası noktasız (مُهْمَل) harflerden oluşan kasîde olarak tanımı yapılmış ve tasannu edebiyatında yaygın olarak kullanılan bir süsleme sanatı olup genellikle makâmelerde görüldüğü belirtilmiştir ${ }^{5}$.

Bir başka kaynakta $\mathrm{da}^{6}$ benzer şekilde tanımlanmış ve cinâs mülemma adı altında cinasın türleri arasında zikredilmiştir. Memlûk 
Dönemi şairlerinden Șafiyuddîn el-Hillî̀'nin bir beyitini noktalı bir beyitini noktasız harflerden nazmettiği şiirinin bir kısmı şöyledir:

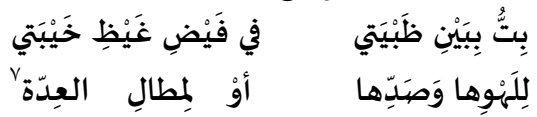

- Geceyi maralımdan ayr geçirdim, ondan mahrum olmamım hiddeti içinde,

- Beni arzuladı mı, arzulamadı mı? Yoksa iddeti (ay hâli) uzadı diye $m i$ ?

Kelime anlamı itibariyle mülemma, Farsça'ya Arapça'dan intikal etmiş ancak edebî bir tür olarak terim anlamını Fars Edebiyatında kazanmıştır. Zira geçmişten bu yana Arapça'ya aşina olan İranlı edîpler ve şairler Arapça kelimeler, deyimler, terkipler ile ibareleri kullanarak eserlerinin muhtevasını zenginleştirme yoluna gitmişlerdir. Zamanla şairler bununla da yetinmeyip bir misra Farsça bir misra Arapça veya bir beyit Farsça bir beyit Arapça şiirler söylemiş ve böylece mülemma adı verilen yeni bir edebî türün temelini atmışlardır ${ }^{8}$.

Fars Edebiyatı'nda ortaya çıkan ve bedî' sanatlardan sayılan mülemmanın uzun bir geçmişi vardır. Nitekim araştırmacılar bu sanatın geçmişini h. IV. yüzyıla kadar götürmüşler ve ilk mülemma şiiri h. IV. yüzyılın ilk yarısında Şehîd-i Belhî (ö.927)'nin söylediği kanısına varmışlardır. Yine Belhî’den sonra Ebû Cafer Endâdî (ö.?) adında başka bir İranlı şairin bu yüzyılın ikinci yarısında bir mülemma şiir söylediği nakledilmiştir?.

Fars dilinde belagate dair en eski eser olarak kabul edilen "Tercümânu'l-Belâğa"da mülemmanın bir belagat terimi olarak "Aynı vezin ve kafiyede bir beyit Arapça bir beyit Farsça söylenen kasidedir. ${ }^{\prime 10}$ şeklinde tanımı ilk kez yapılmıştır. Eserin tespit edilen yazılış tarihinden (h.481-507 arası) ${ }^{11}$ yola çıkacak olursak yukarda da değinildiği gibi Fars edebiyatında mülemmanın h.IV.yy. gibi erken bir dönemde ortaya çıkmış olması bizce makûl görülmektedir.

Mülemmanın beyit sayısı hususunda net bir bilgi yoktur. Ancak çeşitli ilimlere ait geniş kapsamlı terimler ansiklopedisi "Keşşâfu Iștılâhâti'l-Funûn ve'l- 'Ulûm" ile ünlü olan Hintli âlim et-Tehânevî (ö.1745?), mülemmanın beyit sayısını artırmanın câiz olduğunu zikrederek on beyit Arapça ardından on beyit Farsça söyleyen şairler de olduğunu belirtmiştir ${ }^{12}$. 
Fars Edebiyatı'nda mülemma h.IV. yüzyıl şairlerinin şiirlerinde az görülürken h.V. yüzyılın ikinci yarısı ile h.VI. yüzyılın ilk yarısı ve sonrasında daha çok şairin şiirlerinde görülür. Bu şairler arasında Senâîi Gaznevî (ö.h.545), Abdülvâsi-i Cebelî (ö.h.555), Hâkâni-i Şirvanî (ö.h.595), Sa dî-i Şîrâzî (ö.h.691), Mevlânâ Celâleddîn-i Rûmî (ö.h.672), Hâfız-1 Şîrâzî (ö.h.792) ve Molla Câmî (ö.h.898) vardır ${ }^{13}$.

Fars Edebiyatı'nda mülemmalar h.VII. yüzyıla kadar sadece Arapça ve Farsça iken, h.VIII. yüzyılda Türkçe mülemmalar görülmeye başlanmış, daha sonraları ise farklı dillerde de mülemma şiirleri söylenmiştir ${ }^{14}$.

Ortaçağ'ın meşhur seyyahlarından İbn Battûta (ö.1369), Kırım seyahatinde Kıpçaklar'1 zikrettiği bir bölümde Azak Beyi'ne misafir olduğunu anlatırken mülemma hakkında şöyle bir bilgi sunar: ...Ardından Arapça ilâhi söylemeye başladılar. Buna 'kavâl' diyorlardı. Daha sonra Farsça ve Türkçe okumaya başladılar ve buna da 'mülemma' diyorlard $\ldots{ }^{\prime \prime 15}$ Burada da görüldüğü gibi yakın coğrafyada yaşayan milletler arasındaki dil ve edebiyat etkileşimi kaçınılmazdır.

\section{Abdülvâsi-i Cebelî}

İranlı şair Bedîuzzamân Abdulvâsi' b. Abdulcâmi' Gurcistânî-yi Cebelî, Alevi hanedanına mensup olup Gurcistân'da doğmuştur ${ }^{16}$. Doğum tarihi bilinmemekle birlikte vefat tarihi h.555/1160 olarak kaydedilmiştir $^{17}$. Cebelî, Herat'a gitmiş ve yıllarca orada kalarak Nizamiye Medresesi'nde tefsir, hadis, fikıh, kelam gibi zamanının çeşitli ilimlerini öğrenmiştir ${ }^{18}$. Cebelî’nin eserlerini inceleyen Zebihullâh-i Safâ, onun Arap ve Fars Dili Edebiyatları ile İslam kültürü hususunda çok iyi bir eğitim aldığını ifade etmiş ve bunun her iki dilde yazdığı seçkin nazım ve nesir parçalarında açıkça görüldüğünü belirtmiştir. Yine şairin Arapça nesir ve nazımdaki kaleminin gücüne vurgu yapmış, divanında bulunan bir Arapça şiir ile iki mülemmasını bunun en belirgin örneği olarak göstermiştir ${ }^{19}$.

Cebelî'nin divanının yanı sıra risâlelerden oluşan bir nesir koleksiyonu da mevcuttur ${ }^{20}$. Ayrıca Ahmed Fâris eş-Şidyâk'ın (ö.1887) Arap edebiyatı üstadlarından seçme metinleri derlediği eserinde ${ }^{21}$ Cebelî’nin Herat halkına sitem ettiği Arapça bir risâlesi de bulunmaktadır. Arapça risâlesinin böyle bir koleksiyona dahil edilmesi de onun Arap dilini kullanımındaki maharetini göstermektedir.

Abdulvâsi-i Cebelî’nin divanında memdûhlarıyla olan ilişkisi dışında hayatı hakkında çok fazla bilgi bulunmamaktadır. Memdûhları 
arasında Gûrlu ve Selçuklu Sultanlarının, Maveraunnehir, Sîstân, Kirmân ve Loristân atabeklerinin, İran'ın doğusu, batıs1 ve güneyinden bazı emirlerin de bulunduğu otuz küsur kişi vardır ${ }^{22}$. Yine şairin methettiği önemli isimler arasında Tuğrul Tekîn b. Muhammed (ö.?), Behrâmşâh b. Mes'ûd-i Gaznevî (ö. 1157), Sultan Sencer (ö.1157) ve Arslanşah b. Kirmânşah (ö.1142) zikredilebilir ${ }^{23}$. Bu bakımdan divanı onun dönemindeki tarihî bilgiler açısından önem taşımaktadır ${ }^{24}$.

Cebelî, VI/XII. yüzyıl ortalarında döneminin edebiyatında Arapça kelime kullanımının yaygınlaşması açısından ${ }^{25}$ şiir üslûbunun değişmesinde etkili olan Mes'ûd-i Sa'd (ö.1121), Ebu'l-Ferec Rûnî (ö.1107'den sonra) ve Senâî gibi üstadlar zümresinde yer almış ve onlar gibi bu alanda başarılı olmuştur. Ayrıca Cebelî her ne kadar usta bir kaside şairi olarak öne çıkmış olsa da, onun gazel söyleme hususundaki önemini göz ardı etmemek gerekir. Zira, Senâî gibi çeşitli vezinler, kafiyeler, mazmunlar ve temalarda çok sayıda gazel söylemiş ve Fars şiirinin bu çok önemli türüne bağımsızlık kazandırmıştır ${ }^{26}$.

Cebelî'nin, özellikle kasîdelerinde büyük ölçüde tersî (iltizâm), muvâzene, cinas, tezât (tıbak), îhâm gibi lafzî belagat sanatlarından yararlandığı, seçkin şiirlerinde de teşbîh, istiâre, vasf ve medhi ustaca kullandığı görülmektedir. Ayrıca kasidede leffü neşr sanatını ilk kullanan şair olduğu da söylenmektedir ${ }^{27}$. Ancak Cebelî’nin bazı şiirlerinde belagat sanatlarını kullanmada aşırıya gittiği görülür ki, bu da o şiirlerindeki mefhumların anlaşılmasını zorlaştırır ${ }^{28}$.

Cebelî’nin Arapça kelimeler, terkîpler hatta cümleler kullanmada sınır tanımadığı bilinse de, bazı kasidelerinde, gazellerinin birçoğunda, rubaîleri, terkîb-i bendleri ve maktaatlarında sade ve akıcı bir üslûp da kullandığı görülür ${ }^{29}$.

\section{Abdülvâsi-i Cebelî’den Bir Mülemma}

Cebelî’nin divanında bulunan iki mülemma kasidesinden biri şöyledir:

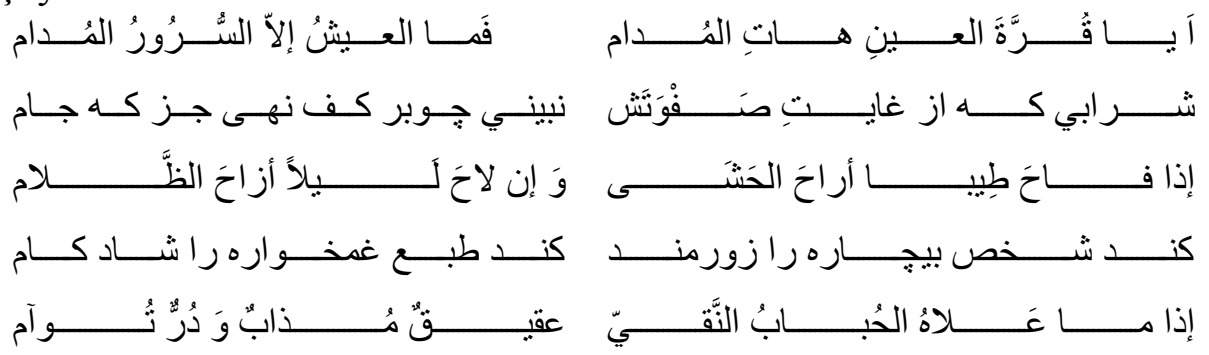




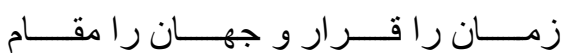

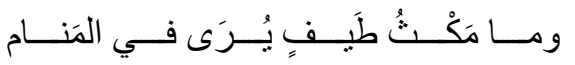

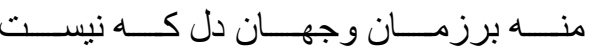

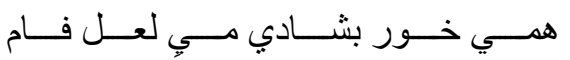

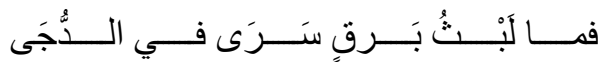

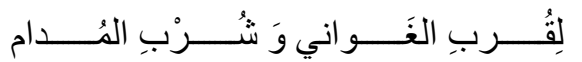

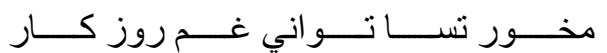

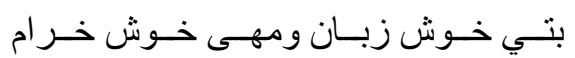

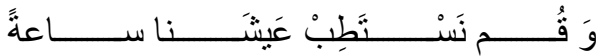

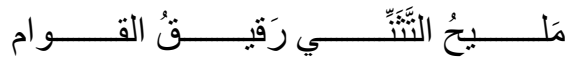

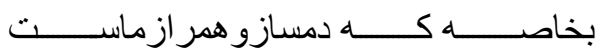

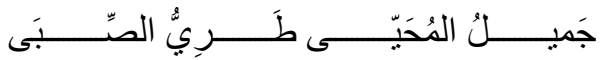

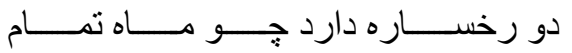

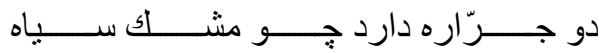

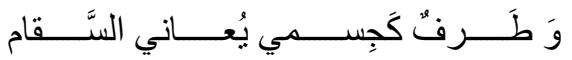

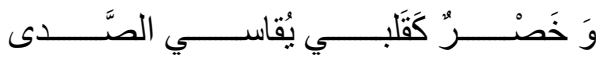

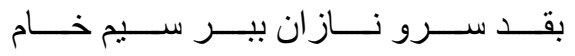

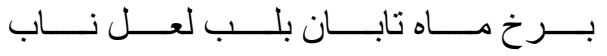

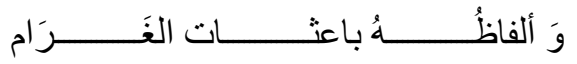

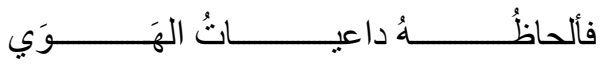

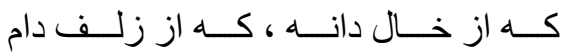

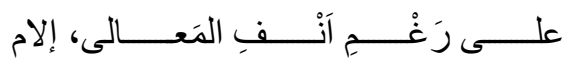

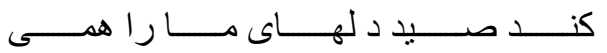

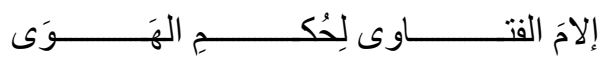
كهــــــى نفــــس آز اد كـــــرده غــــــلام

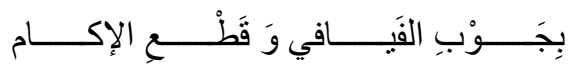

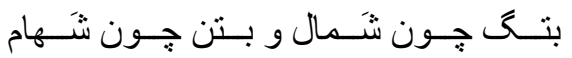

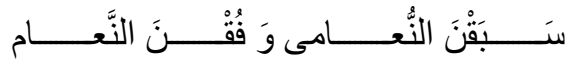

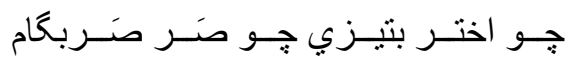

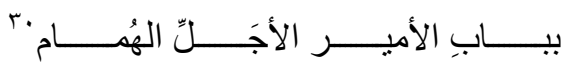

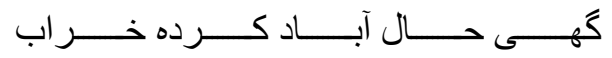

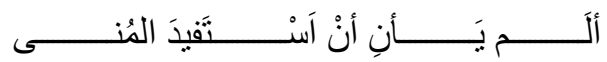

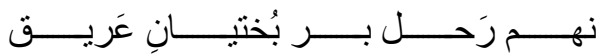

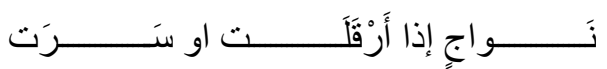

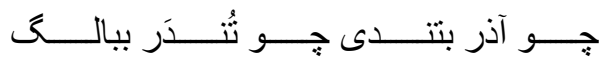

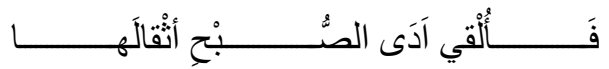

1 Ey sevgili! Şarap getir, zira yaşam şarabın verdiği kesintisiz hazdan başka bir şey değildir.

2 Son derece hâlis şarabı göremezsin, eline kadehin dışında bir şey koymadiğın zaman,

3 (Öyle bir şarap ki), kokusu yayılırsa içi rahatlatır, gece parlarsa karanliğ aydınlatır.

4 Çaresiz insanı güçlü, kederli insanı mutlu kılar.

5 Üzerinde saf köpükler yükseldiği zaman, âdeta eritilmiş akîk ve bir çift inci. 
6 Zaman ve dünyaya gönül bağlama; zira zaman için istikrar, dünya için makam yok.

7 Ne zifiri karanlıkta geçip giden şimşeğin, ne de uykuda görülen ışı̆̆ın (rüyanın) kalıcılı̆̆ı var.

8 Gücün yettiğince feleğin gamını çekme, lâl rengi şarabı mutlu bir şekilde iç.

9 Kalk bir süre bile olsa haz alalım hayattan, güzel kadınlar ve şarapla,

10 Özellikle tatlı dilli ve güzel (nazlı) yürüyen sevgili her dâim yanımızda,

11 (Öyle bir sevgili ki), yüzü güzel, teni körpe, salınması hoş, endâmı zarîf (ince),

12 Misk gibi kokan zülüfleri, dolunay gibi yanakları var,

13 Susuzluktan acı çeken kalbim gibi (kırllgan) bir beli, hastalıktan muzdarip olan bedenim gibi (direnen) bir bakışı (var).

14 Yanağı parlayan ay, dudă̆ lâl gibi; boyu nazlı servi, göğsü saf gümüş̧ gibi,

15 Bakışları aşkı çağırır, sözleri sevdaya salar.

16 Kâh ben yemiyle, kâh zülüf tuzağıyla avlar gönüllerimizi,

17 O halde yüce mevkilerin inadına, aşkın hükmünü veren fetvalar nereye kadar? Niçin?

18 Bazen âbâdl viraneye, bazen özgürü köleye çevirir,

19 Artık çölleri dolaşıp, tepeleri aşarak arzulardan yaralanmamın vakti gelmedi mi?

20 Yolluğumu koyuyorum, koşuda kuzey rüzgârl gibi, vücudu çevik, asîl develer üzerine,

21 Öyle hızlı develer ki, hızlandiğı zaman güney rüzgârını geride bırakıp deve kuşunu geçerler.

22 Ateş gibi süratli, sesi gökgürültüsü gibi, Ahter yıldızı gibi parlak, adımı firtına gibi,

23 Sabah vakti, yüklerini Yüce emire götürürüm.

"Mutekârib" vezninde nazmedilen bu kasidenin dâhilî plânına bakıldığında, şairin Arap Edebiyatındaki geleneksel kasideden etkilendiğini söylemek mümkündür. Zira bu kaside şarap ve sevgili tasviri ile başlayan bir nesîb (teşbîb) bölümü, yolcuğunu anlatıp atını tasvir ettiği bir rahîl (tasvir) bölümü ve kasidenin asıl konusu olan medih bölümünden oluşmaktadır. Ancak şairin bir girizgâh ile medih 
bölümüne geçiş yaptığ 1 görülse de kasidede bu bölümün devamı bulunmamaktadır. Dolayısıyla bütünlük açısından ele aldığımızda söz konusu mülemma kasidenin devamının elimize ulaşmamış olabileceği kanaatindeyiz. Nitekim yazma eserlerin karşılatırmasını yaparak Cebelî’nin divanını derleyen muhakkik de, şairin bazı şiirlerinin bulunduğu nüshalarda eksiklikler olabileceğini tespit etmiştir ${ }^{31^{3}}$.

Mülemmanın muhteviyatına bakıldığında rindâne bir üslûbun varlığından söz etmek mümkündür. Zira dünyanın gelip geçici olduğunu, makamın ve şöhretin öneminin olmadığını ifade eden şairin, şarap içerek ve güzel kadınlara yönelerek yaşamdan zevk almanın önemini dile getirdiği görülmektedir.

Cebelî'nin, sevgiliyi tasvir ederken جميل المحيى (yüzü güzel), رقيق الحاظه (endamı zarîf) gibi müzekker (eril) sıfatları ve yine المديc (القوام (bakışları), الفاظه (sözleri) gibi tamlamalarda eril olan \& (o erkek) zamirini kullandığı görülmektedir. Dolayısıyla sevgilinin neden bir kadın değil de erkekmiş gibi tasvir edildiği sorusu akıllara gelmektedir. Arap, Fars ve Türk Edebiyatlarında zaman zaman görülen bu durum, edebiyatta güzellik timsali olarak sevgili tipinin idealize edilmesi geleneğinin bir sonucu olarak düşünülebilir. Bir başka deyişle burada önemli olan sevgilinin cinsiyeti değil hayâl edilen ideal güzelliğin tasviridir. Zira şair sevgili tasvirine geçmeden hemen önceki "Kalk bir süre bile olsa yaşamımızdan zevk alalım, şarap içerek ve güzel kadınlara yakınlaşarak" beyitinde "güzel kadınlar( الغواني)" ibaresini kullanmıştır. Bu da şairin hemcinsini değil, hayâlindeki güzel ve ideal kadını tasvir ettiğini göstermektedir.

Cebelî’nin, söz konusu mülemma kasidesinde Arapça bilgisini ustaca kullandığı ve başarılı tasvirler yaptığı gözden kaçmamaktadır. Ayrıca şiirini nazmederken belagat sanatlarından da etkin bir şekilde yararlandığı görülmektedir. Nitekim şair mülemmasının daha ilk beyitinde (يا قُرَّة العََِْنِ ) "Ey göz aydınlığı (göz bebeği, göz nuru)" anlamına gelen ibare ile sevgiliyi kastederek istiare sanatı yapmıştır. Yine ilk mısranın son tefilesinde "şarap" anlamına gelen "المُدام" kelimesi ile, ikinci mısrada "kesintisiz, sürekli, devamlı" anlamına gelen "المُدام" sözcügüüü kullanarak tam cinas yapmıştır.

Kasîdenin geneline bakıldığında hem Arapça hem Farsça beyitlerde bir mûsikî, ahenk ve uyum göze çarpmaktadır. Zira şair, birkaç beyit hariç her beyitin mısraları arasında paralel bir şekilde vezin birliği 
yaparak muvâzene sanatını başarılı bir şekilde tatbik etmiştir. Kasidenin

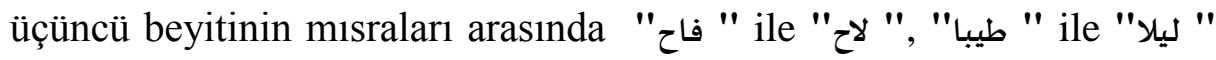
ve " sözcüklerindeki vezin uyumu, şairin çokça kullandığ1 muvâzene sanatına örnek gösterilebilir. Ayrıca şairin bu sanatı Arapça beyitlerde de sık sık kullanması, dile olan hâkimiyetini ve kelime dağarcığının zenginliğini açıkça göstermektedir.

\section{Sonuç}

Yakın coğrafyada yaşayan milletlerin dil ve edebiyat açısından karşılıklı etkileşimi kaçınılmazdır. Geçmişten bu yana İslam medeniyetinin tesiri altında kalan Fars Edebiyatı'nda, bir ilim dalı olarak öne çıkan Arapça'nın öğrenilmesi ve kullanılması bir ayrıcalık olarak görülmüştür. Bunun doğal bir sonucu olarak şairler Farsça şiirleri arasına Arapça mısra ya da beyitler serpiştirmişler ve böylelikle mülemma şiiri X. yüzyılda Fars Edebiyatı'nda ortaya çıkmıştır. Ancak Abbasî Dönemine tekabül eden bu dönemde Farsça'nın Arapça'ya etkisi bilinse de, mülemma türü şiir Arap Edebiyatı'nda görülmemektedir.

Fars Edebiyatı'nda Arapça bilgisini etkin bir şekilde kullanan seçkin şairlerden Cebelî'nin başarılı tasvirler yaptığı ve edebî sanatları ustaca kullandığı mülemma kasidesi, onun Arap diline olan hâkimiyetini ve kelime dağarcığının zenginliğini açıkça göstermektedir. Ayrıca ülkemizde yeterince incelenmeyen mülemma şiiri, Farsça ile Arapça arasındaki dil ve edebiyat etkileşimini yansıtması açısından önem arzetmektedir. 


\section{Kaynakça}

'Akkâvî, İn'âm Fevvâl, el-Mu'cemu'l-Mufașsal fì 'Ulûmi’l-Belâğa, Dâr'ul-Kutubi'l-'İlmiyye, 2.bs, Beyrut 1996.

el-Cevherî, İsmail b. Hammâd, eș-Ṣıhâh,thk. Ahmed Abdulğafûr 'Atṭâr, c.IV, Dâru'l-'İlmi li'l-Melâyîn, 4.bs., Beyrut 1987.

el-Ferâhîdî, Halîl b. Ahmed, Kitâbu'l-'Ayn, thk. Mehdi el-Maḥzûmî, c.II, Dâr ve Mektebetu'l-Hilâl, Beyrut Bty.

İbn Bațûța, Ebû Abdullah, Rıhletu İbn Battûța, nşr. Ekâdîmiyyetu'lMemleketi'l-Mağribiyye, c.II, Rabât 1417 h.

İbn Dureyd, Ebûbekr b.el-Hasan, Cemheretu'l-Luga, thk. Remzî Munîr Ba'lebekkî, c.II, Dâru'l-'İlmi li'l-Melâyîn, Beyrut, 1987.

İbn Manẓûr, Muhammed b. Ebî Faḍl, Lisânu'l-'Arab, c.VIII, Dâru Șâdır, 3.bs, Beyrut 1414 h.

er-Râdûyânî, Muhammed b.'Omar, Kitâb Tercümâni'l-Belâğa, nşr. Ahmed Ateş, İbrahim Horoz Basımevi, İstanbul 1949.

Rasûlî, Hüccet, Mülemma' der Şi 'r-i Farsî, byy. 1396.

Safâ, Zebihullâh, Tarîh-i Edebiyât der Iran, c.II, 13.bs, Tahran 1373.

Safâ, Zebihullâh, Divân-i Abdulvâsi-'i Cebelî Be İhtimâm u Teshîh u $T e^{‘} l i \hat{k}$, İntişarât-i Emîr-i Kebîr, 2.bs, Tahran bty.

eş-Şidyâk, Ahmed Fâris, et-Tuhfetu'l-Behiyye ve't-Turfetu'ş-Şehiyye, Dâru'l-Afâkịi'l-Cedîde, Beyrut 1981.

Tibyâniyân, Dânişnâme-i Edeb-i Farsî; Edebî Farsî̀ der Afganistan, c.III, Tahran 1378.

et-Tehânevî, Muhammed b. Ali, Keşşâfu Ișțlâhâti 'l-Funûn ve'l- 'Ulûm, çev. Abdullah el-Hâlidî, Beyrut 1996.

Yakub, Emîl Bedî‘, Mevsûa'tu 'Ulûmi'l-Luğati'l-'Arabiyye, c.IX, Dâr'ul-Kutubi'l-'İlmiyye, 9.bs, Beyrut 2006.

ez-Zemahșşerî, Ebu'l-Kâsım, Esâsu'l-Belâğa, thk. Muhammed Bâsil 'Uyûnu's-Sûd, c.II, Dâr'ul-Kutubi'l-'İlmiyye, Beyrut 1998. 
${ }^{1}$ İsmail b. Hammâd el-Cevherî, eș-Ṣlhâhh, thk. Ahmed Abdulgafûr 'Atțâr), Beyrut 1987, c.IV, s.1281; Muhammed b. Ebû Fạ̣l İbn Manẓ̂r, Lisânu'l- 'Arab, Beyrut 1414 h., c.VIII, s.324.

${ }^{2}$ Ebu'l-Kâsım ez-Zemahşerî, Esâsu'l-Belaga,thk.Muhammed Bâsil 'Uyûnu's-Sûd, Beyrut 1998, c.II, s.181.

${ }^{3}$ Halîl b. Ahmed el-Ferâhîdî, Kitâbu'l-'Ayn, thk. Mehdi el-Maḥzûmî, Beyrut Bty., c.II, s.155; Ebûbekr b. el-Hasan İbn Dureyd, Cemheretu'l-Luga, thk. Remzî Munîr Ba'lebekkî, Beyrut, 1987, c.II, s.949; İbn Manẓûr, a.g.e., s.325.

4 Aynı eser, s.325; el-Ferâhîdî, a.g.e., s.155; el-Cevherî, a.g.e., s.1281; İbn Dureyd, a.g.e., s.949.

${ }^{5}$ Emîl Bedî‘ Yakub, Mevsûa 'tu 'Ulûmi’l-Lügati’l-Arabiyye,Beyrut 2006, s.81.

6 İn‘âm Fevvâl 'Akkâvî, el-Mu'cemu'l-Mufașṣal fì 'Ulûmi’l-Belaga, Beyrut 1996, s.522,523.

7 Ayni eser, s.523.

${ }^{8}$ Hüccet Rasûlî, Mülemma' der Şi'r-i Farsî, byy.1396, s. 9.

9 Ayni eser, s. 9.

${ }^{10}$ Muhammed b. 'Omar er-Râdûyânî, Kitâb Tercümânu'l-Belaga, nşr. Ahmed Ateş, İstanbul 1949, s.107.

${ }^{11}$ Ayni eser, 34.

12 Muhammed b. Ali et-Tehânevî, Keşşâfu Ișțlâhâti'l-Funûn ve'l-'Ulûm, çev. Abdullah el-Hâlidî, Beyrut 1996, s.1643.

${ }^{13}$ Hüccet Rasûlî, a.g.e. s. 10.

${ }^{14}$ Detaylı bilgi için bkz.Hüccet Rasûlî, a.g.e.

${ }^{15}$ Ebû Abdullah İbn Baț̣̂ța, Rıḥletu İbn Bațtûta, nşr. Ekâdîmiyyetu'l-Memleketi'lMagribiyye, Rabât h.1417, c.II, s.222,223.

${ }^{16}$ Zebihullâh-i Safâ, Tarîh-i Edebiyât der Iran, Tahran hş. 1373, c.II, s.650.

${ }^{17}$ Zebihullâh-i Safâ, Divân-i Abdulvâsi'-i Cebelî Be İhtimâm u Teshîh u Te'lîk, Tahran 1339, s.17.

18 Tibyâniyân, Dânişnâme-i Edeb-i Farsî; Edebî Farsî der Afganistan, Tahran 1378, c.III, s.687.

${ }^{19}$ Zebihullâh-i Safâ, Divân-i Abdulvâsi', s.15.

${ }^{20}$ Tibyâniyân, a.g.e., s.688.

${ }^{21}$ Ahmed Fâris eş-Şidyâk, et-Tuhfetu'l-Behiyye, Beyrut 1981, s.170.

22 Tibyâniyân, a.g.e., s.687.

${ }^{23}$ Zebihullâh-i Safâ, Tarîh-i Edebiyât, s.651.

${ }^{24}$ Tibyâniyân, a.g.e., s.687.

${ }^{25}$ Zebihullâh-i Safâ, Tarîh-i Edebiyât, s.651.

${ }^{26}$ Zebihullâh-i Safâ, Divân-i Abdulvâsi', s.22,23.

${ }^{27}$ Tibyâniyân, a.g.e., s.688.

28 Tibyâniyân, a.g.e., s.688. 
${ }^{29}$ Zebihullâh-i Safâ, Divân-i Abdulvâsi', s.21,22.

${ }^{30}$ Ayni eser, s.485,486.

${ }^{31}$ Ayni eser, s.4,5. 